\title{
12 Tentativas para una nanofilología de la literatura latinoamericana mundial
}

Una hipótesis que ya he introducido sostiene que la mediación produce, por supuesto, literatura, pero también texto (Marling, Thompson, Mani, Brouillette/ Doody), y que esa mediación, por lo tanto, debe ser considerada no solo coproductora sino también coautora. Invertida, la tesis diría que en el texto publicado y convertido en libro se pueden "leer" las marcas de la mediación o, dicho de otro modo, que los diferentes actores que intervienen en la cadena productiva dejan huellas en el texto. Esta tesis, como ya he adelantado, vale principalmente para la literatura mundial, donde los actores que hacen posible la publicación y puesta en circulación -en comparación con lo que sucede en las literaturas locales, donde un solo sujeto puede asumir múltiples o todas las funcionesnecesariamente se multiplican. Bajo estas premisas, voy a intentar leer en lo que sigue textos que -a diferencia de lo que sucedió con "Tadeys"-, en efecto fueron publicados por Anagrama y, por lo tanto, acogidos en la literatura latinoamericana mundial.

También guía este apartado la idea de que la sociología de la literatura es insuficiente para pensar las dinámicas literarias; esto es, que someter a examen el campo literario no alcanza para explicar la literatura, aunque, invirtiendo los términos, tampoco un análisis textual clásico, filológico, basta para dar cuenta de por sí de los procesos que convierten a la literatura en literatura mundial. Propongo, no obstante, que el ejercicio de close reading que voy a ensayar sería una herramienta complementaria para iluminar mejor, incluso mejor que cualquier distant reading, principios que gobiernan la producción de literatura mundial, en particular latinoamericana. Un tipo de close reading como el que quiero activar supone que la sociología con frecuencia olvida que las tramas textuales no son intercambiables, no son valores vacíos que pueden ser ignorados, sin que la evaluación corra el riesgo de incurrir en graves desaciertos, sino que constituyen, precisamente, el elemento que en última instancia organiza y sostiene, aunque sea como excusa, las dinámicas y posicionamientos en el campo.

He observado, siguiendo a Marling, que sin duda muchos gatekeepers participan más o menos directamente en el proceso de escritura y acabado final para adecuar el producto lo mejor posible a las condiciones de recepción que, ante todo en el nivel de la literatura mundial, quien asume formalmente la función autor por regla general desconoce. Se trata de que aquellos textos que no han 
nacido plenamente traducidos (born-translated, Walkowitz), ${ }^{1}$ deben ser acondicionados, depurados, eventualmente, de sus culturemas e incompatibilidades de mayor relieve como para que el mercado de recepción en algún momento pueda asimilarlos. En las próximas páginas voy a tratar de reconstruir momentos de tal proceso a partir de fuentes documentales heterogéneas para, finalmente, examinar algunos pasajes de literatura de ficción efectivamente publicada.

Ya he adelantado en el apartado II.1 un episodio en el que el escritor colombiano Evelio Rosero imputaba al equipo de corrección de Anagrama una transformación para él inaceptable de su manuscrito de Juliana los mira (1987) y reclamaba que "cualquier regionalismo, español o mexicano o argentino enriquece el acervo lingüístico, fortalece y universaliza el idioma”. Y también que "En cierto modo, fue también mi primera experiencia con las traducciones. Pues, de hecho, siendo como era un escritor en español, me estaban traduciendo al español”. En estas palabras están contenidos dos problemas que creo conveniente hacer explícitos: que toda corrección, cuando se aplica a textos que trascienden fronteras culturales o nacionales, aunque sea en la misma lengua -como es el caso de cualquier texto que circula de América Latina a España-, sería una traducción en la medida que nunca va a ser solo una corrección de erratas. También que esa riqueza léxica que pretende vindicar Rosero difícilmente se puede sostener cuando un texto aspira a entrar en dinámicas de circulación que van más allá de su contexto de emergencia. La fórmula, planteada en breve, diría que cuanto mayor es la distancia cultural de proyección, menor es la posibilidad de que el repertorio lingüístico y cultural contenido en un texto se mantenga "fiel" a su contexto. Si se los ubica sobre este trasfondo, los reclamos de Rosero pecan, sin duda, de cierta inocencia, pues su manuscrito solo estaba siendo ajustado como para que pudiera insertarse más fácilmente en el circuito de la literatura mundial, algo que, por lo demás, él sin duda anhelaba. En otras palabras, puesto que "Juliana los mira" no había nacido traducido, los correctores/traductores estaban creando condiciones como para favorecer su asimilación en el mundo o, al menos, en el mercado que le

\footnotetext{
$1 \mathrm{Al}$ respecto del término, Walkowitz anota: "many novels do not simply appear in translation. They have been written for translation from the start. Adapting a phrase for artworks produced for the computer ('born digital'), I call these novels born translated. Like born-digital literature, which is made on or for the computer, born-translated literature approaches translation as medium and origin rather than as afterthought. Translation is not secondary or incidental to these works. It is a condition of their production. Globalization bears on all writers working in English today. However, it bears on them differently. Some works of fiction are sure to be translated. Others hope to achieve it. Some novelists are closely tied to the mass market, some to prestige cultures, and others to avant-garde communities. But even those novelists who don't plan on translation participate in a literary system attuned to multiple formats, media, and languages. Born-translated novels approach this system opportunistically” (3-4).
} 
abriría las puertas del mundo. Finalmente, no obstante, "Juliana los mira" no fue corregido/traducido y su suerte en Anagrama no tuvo, por tal razón, mayor trascendencia; por eso, tampoco acá le voy a dedicar mayor atención.

Me interesa retomar rápidamente un caso ya presentado desde otra óptica en II.3 que supera el plano de la traducción intralingüística para ubicarse en el de la interlingüística. Lo retomo porque ofrece precisiones acerca de cómo actúa la mediación, más allá del obvio proceso de adaptación que la traducción de por sí supone. Como he comentado, después del reconocimiento con el Premio Biblioteca Breve en 1999, En busca de Klingsor, de Jorge Volpi, fue ofrecido al circuito editorial internacional para ser traducido. Muchas editoriales del mundo, en parte porque venía amparado por un premio que revitalizaba una tradición de éxito y prestigio, evaluaron la adquisición de los derechos de traducción. Varias los adquirieron y, en efecto, publicaron traducciones del libro en diferentes lenguas. Para el caso del mercado germanohablante el libro presentaba, sin embargo, un desafío agregado, pues el argumento aborda episodios de la historia alemana reciente que podían, por lo tanto, no resultar convincentes, o al menos ser objeto de cuestión, para la potencial recepción. La traducción y publicación, finalmente, se concretó en 2001 bajo el nombre Das Klingsor-Paradox por cuenta de la editorial Klett-Cotta y la traductora Susanne Lange, pero antes fue evaluado, positivamente, por medio del informe de lectura redactado por Michi Strausfeld para la editorial Suhrkamp que se conserva en el Deutsches Literaturarchiv Marbach. Además del pasaje anteriormente examinado en el capítulo II, se puede encontrar el siguiente:

Jorge Volpi hat mire in einem Telefonat erläutert, daß er drei Monate in Deutschland vor Ort recherchiert hat, um Dörfer und Städte seines Romans kennenzulernen. Er spricht ein rudimentäres Deutsch, seine Sekundärliteratur ist vorwiegend Englisch, aber auch Italienisch und Französisch (am Ende des Romans angeführt). Er sagt, daß er das Leben und die Forschungen der Wissenschaftler genau wiedergibt, dank intensiver Sekundärliteratur. Was die deutsche Geschichte betrifft, denkt er, daß er ebenfalls sehr genau gearbeitet hat... aber dennoch seien Fehler natürlich nicht auszuschließen. Dann ist er gerne bereit und sogar dankbar, sie zu korrigieren - evtl. auch einige Zusammenfassungen (wie die des 20. Juli) für ein deutsches Publikum zu reduzieren. (Kennen deutsche Leser seines Alters alle diese Vorgänge?).

In der soeben erschienen 2. Auflage seien bereits etliche Fehler korrigiert worden Entfernungen, Jahreszahlen. „Aneneerbe“ sei in der engl. Literatur immer ohne „h“ geschrieben, was sicher falsch ist. Da wird es bestimmt noch etliche kleinere Korrekturen geben. (2) ${ }^{2}$

2 "Jorge Volpi me ha comentado por teléfono que investigó directamente en Alemania durante tres meses para conocer pueblos y ciudades de su novela. Habla un alemán rudimentario, su literatura secundaria es principalmente en inglés, pero también en italiano y francés (listada al 
La lectora deja constar así que, en una comunicación telefónica, Volpi le habría dado detalles del trabajo de investigación que realizó para componer En busca de Klingsor: recorrió durante tres meses Alemania y consultó abundante material bibliográfico -que aparece consignado en el libro publicado- en inglés, italiano y francés. Con apoyo en esta bibliografía, el escritor asegura haber reconstruido con exactitud no solo episodios históricos sino también la vida de los científicos alemanes retratados en la novela. Lo cual, aclara el informe, no excluye la posibilidad de que todavía sea necesario corregir errores para agregar a continuación que Volpi no solo estaría dispuesto a ello sino también agradecido. $\mathrm{Al}$ cambiar el marco de recepción, del que representa un público hispanohablante a uno germanohablante y, por lo tanto, más familiarizado con detalles de la historia alemana, los riesgos de que ciertos errores, naturales para el caso, sean advertidos aumentan, de modo que, para que la reinserción no derive en algún tipo de bochorno, una revisión y eventual corrección en este nivel sería necesaria. Se trata de que Volpi, según se extrae de este informe, sería más sensible y abierto que Rosero a las reubicaciones culturales de sus respectivas escrituras. Tal es así que el informe también consigna que el escritor estaría dispuesto a reducir notas históricas de su texto en función de un público alemán ("für ein deutsches Publikum"). La circulación, admite Volpi, implica necesariamente cambios en los textos, básicamente adaptaciones a horizontes de expectativas condicionados por sus propios rasgos culturales; modificaciones, vale decir, que en su expresión más visible toman la forma de traducciones interlingüísticas, pero, como queda claro, no se reducen a ellas.

Pero veamos cómo la acción de los gatekeepers deja "huellas" concretas o manifestaciones de su intervención directa o indirecta en los textos publicados; esas huellas, precisamente, que Rosero cree haber impedido en su texto.

César Aira, hoy un escritor con un importante reconocimiento internacional, posee una producción temprana que desde los mismos títulos se inscribe en la tradición argentina más característica; me refiero, fundamentalmente, a Moreira

final de la novela). Afirma que él reproduce las investigaciones y la vida de los científicos de manera exacta a partir de la consulta minuciosa de bibliografía secundaria. En lo que respecta a la historia de Alemania, él cree haber trabajado de manera también rigurosa... pero que, de todas maneras, no habría que excluir la posibilidad de algunos errores. Por esta razón, él ya se ha manifestado de acuerdo e incluso agradecido con eventuales correcciones. Dado el caso, también estaría dispuesto a reducir algunos resúmenes (como el del 20 de julio) en función del público alemán (¿conocen todos los lectores alemanes de su edad esos acontecimientos?).

En la recientemente aparecida segunda edición ya se habrían corregido algunos errores distancias, años-. 'Aneneerbe' habría aparecido en la bibliografía en inglés siempre sin 'h', lo cual sin duda es falso. Ahí también habría que hacer algunas pequeñas correcciones” [la traducción es mía]. 
(Buenos Aires: Achával Solo, 1975), Ema, la cautiva (Buenos Aires: Editorial de Belgrano, 1981) y La luz argentina (Buenos Aires: CEAL, 1983). Se trata en los tres casos de publicaciones realizadas en Buenos Aires por editoriales de circulación localizada, y con una escasa, fragmentaria y tardía recepción internacional. La traducción de Ema, la cautiva al alemán, por ejemplo, data de 2004, cuando Embalse (Buenos Aires: Emecé, 1992), fue traducida en el 2000, ocho años después de su aparición en original y, sin embargo, cuatro antes que Ema. Digamos, entonces, que hay un Aira primigenio que pertenece, fundamentalmente, a la literatura local/nacional y que presenta ciertas resistencias a la puesta en circulación internacional, y un Aira posterior que, paulatinamente, va a ir evolucionando hacia el escritor de la literatura mundial, que, por ejemplo, puede celebrar Patti Smith en 2015 en las páginas del The New York Times, y que le va a abrir algunas puertas en el mercado internacional al primer Aira.

En 1997, sin embargo, la escritura de Aira ya presenta síntomas de haber abandonado su arraigo cultural para, así, poder proyectarse a territorios más vastos. En El congreso de literatura, el narrador homodiegético, un escritor/ científico argentino, cuenta una serie de aventuras sucedidas en Venezuela donde se encuentra con motivo de un congreso de literatura. En un momento dado la narración toma la forma que sigue: "me compré un traje de baño y a partir del día siguiente empecé a pasar las mañanas y las tardes en la piscina” (38). ${ }^{3}$ Dichos en voz de un narrador que se presenta como argentino, los términos “traje de baño" y "piscina” suenan impostados, es decir, colocados en su boca por razones que lo exceden. De un narrador argentino, siempre y cuando se esté dirigiendo a un auditorio local, cabría de esperar los más naturales "malla” y “pileta”. Vocablos que, en el diccionario de la RAE, incluyen las entradas -y aclaraciones- que transcribo a continuación:

pileta

6. f. Arg., Bol., Par. y Ur. piscina (\| construcción que contiene gran cantidad de agua). malla

9. f. Arg., Bol. y Ur. bañador (II prenda para bañarse).

Para encontrarse con el término más regional “pileta”, que bien podría ser algo ajeno a Aira, basta, sin embargo, con revisar la producción anterior del mismo escritor. En Los fantasmas (Buenos Aires: Grupo Editor Latinoamericano 1990),

3 Cito de la edición de Tusquets de 1999. La primera edición apareció en Mérida, Venezuela, en 1997 como coedición de la Universidad de Los Andes y la Fundación Casa de las Letras "Mariano Picón Salas”. 
por ejemplo, el narrador -ahora uno heterodiegético y, en principio, sin pertenencia cultural definida- informa que "Terminadas las uvas, los niños se escaparon, sin zapatos, a jugar en el hueco de la pileta, donde daba todo el sol. Pero les encantaba, casi como si la pileta estuviera llena y chapotearan en la onda fresca" (31). A la luz de este ejemplo, la pregunta natural que surge es qué conduce de un uso al otro, o, con otras palabras, por qué el registro localizado -de "Arg., Bol., Par. y Ur."- de un narrador que no necesita exhibir marcas de pertenencia para sostener su verosimilitud evoluciona hacia uno que se expresa en un registro deslocalizado, y también inverosímil, a pesar de ser presentado dentro del universo narrativo como argentino. Creo no equivocarme si a esta pregunta respondo con la hipótesis que guía este apartado: el Aira de 1997 ya es uno destinado a insertarse en los canales de la circulación internacional, si sus textos, al menos desde entonces, no nacen traducidos, sí son susceptibles de ser adaptados a una codificación sin arraigo cultural, es decir, no dependiente -o no tan dependiente como Moreira- de un contexto y una tradición literaria específicos.

En 2002 Aira - uno que ya da muestras de poder moverse cómodo en el circuito de la literatura mundial- publica Varamo en Anagrama. Se trata de una publicación "anómala", tanto en lo que refiere a la serie que conforma con la producción general de Aira como en lo que respecta al catálogo de Anagrama: de las aproximadamente cien "novelitas" publicadas hasta el momento bajo el nombre Aira (Zunini), solo Varamo apareció en Anagrama. De modo que ni Aira es exactamente un escritor característico de Anagrama, como lo puede ser Guadalupe Nettel o Alan Pauls, ni Anagrama -como si lo podría ser Mansalva o Beatriz Viterbo- la editorial que mejor representa el proyecto del escritor. Varamo estaría informando, por lo tanto, de un circunstancial pero significativo intercambio de valor simbólico: por medio de su publicación, Anagrama habría adquirido parte del prestigio de Aira y la posibilidad de exhibir en su catálogo el nombre acaso más destacado de la literatura en lengua castellana reciente, y Aira, a su vez, parte del prestigio del que se vale Anagrama para insertar sus publicaciones en un lugar privilegiado del circuito internacional.

Desde una perspectiva heterodiegética, fuertemente distanciada del protagonista y de los hechos, Varamo narra el proceso mediante el cual el personaje homónimo, un empleado público panameño sin relieve y sin antecedentes en la escritura, escribe "la celebrada obra maestra de la moderna poesía centroamericana El Canto del Niño Virgen” (8). Pero, además de ser un relato, como suele suceder en la literatura aireana, Varamo también reclama una lectura que lo aborde como un ensayo sobre el fenómeno de la escritura.

Ahora bien, si Evelio Rosero entre sus reclamos al equipo de corrección de Anagrama, consignó lo siguiente: "En Juliana, donde yo escribía, por ejemplo, debe ser que Juliana está enferma, los correctores corregían: debe de ser, y ese 
debe de era para mí peor que un martillo en los tímpanos”, en Varamo la perífrasis verbal "deber de" con valor de suposición -infrecuente en Argentina- aparece fuertemente regulada según convenciones gramaticales. Su uso sistemático en Varamo (17, 29, 54, 104, etc.), a su vez, contrasta con la flexibilidad o directamente el rechazo de la norma en publicaciones anteriores, menos mediadas y más localizadas: “Tú debes ser la Patri” (85), dice por ejemplo, el personaje chileno Roberto en Los fantasmas. El narrador, por su parte, uno que, además de observar rigurosamente la norma, no posee marcas diferenciales de ningún tipo, puede ser caracterizado como una voz por completo extraterritorial: no es de ningún modo panameño, lo que vale para Varamo, pero tampoco se lo podría identificar como argentino o porteño, como a Aira. Del mismo modo que en el caso de los personajes de Nettel que veremos a continuación, este narrador no posee pertenencia de ningún tipo, pero, a diferencia de lo que sucede con los de ella, tampoco en el nivel diegético esa voz aparece signada en términos locales, nacionales o siquiera regionales. El registro que Aira le asigna a su narrador resulta, por lo tanto, imposible de ser asociado con alguna o varias locaciones en la geografía del castellano; se pronuncia, acaso, desde un lugar abstracto en la literatura. Pero antes que la suspicacia en relación con la observación de la norma -que bien puede ser una hipercorrección del mismo Aira- y la señalización del desprendimiento de cualquier arraigo territorial -lo que sin duda facilita la circulación internacional del texto-, me interesa destacar, no obstante, un elemento intrínseco al relato.

César Aira vale por un escritor siempre dispuesto a correr riesgos formales, e interesado por el arte conceptual y de vanguardia, con Marcel Duchamp como uno de sus referentes centrales. Varamo no se aparta, en principio, del cauce principal que delinea su producción. Cabría, sin embargo, establecer una distinción que puede ser clave para comprender la inscripción de Aira en el catálogo de Anagrama y también en la literatura (latinoamericana) mundial. Ocurre que Varamo, antes que ser un texto experimental y aunque efectivamente lo fuere, es una reflexión -bastante transparente y enunciada por una voz sin dependencia de algún contexto específico-sobre la literatura experimental. Aira escribe y medita alegóricamente sobre producciones radicales como la de Duchamp, pero también, antes y en un nivel más íntimo, sobre la de Osvaldo Lamborghini -como ya se vio, inadmisible en Anagrama- y la del performer, poeta y dramaturgo Emeterio Cerro. Varamo es, de este modo, una reflexión sobre las formas radicales de la literatura, pero no es exactamente literatura experimental. "El Canto del Niño Virgen" -observa el narrador- "entra en la categoría de la llamada 'literatura experimental', como que es un ejemplo sobresaliente de las vanguardias latinoamericanas de las primeras décadas del siglo" (64). Este artefacto experimental, “obra maestra de la moderna poesía 
centroamericana”, va a aparecer, sin embargo, tematizado en un texto en prosa, como parte de la serie "Narrativas hispánicas" de Anagrama, y en un nivel tan difuminado que ni siquiera se lo registra como cita. Así -y esto es tal vez lo que permite la admisión de Varamo en Anagrama-, por medio de un procedimiento de elisión, la poesía experimental latinoamericana, invocada como objeto aurático, queda, sin embargo, sustituida por un relato en prosa más o menos convencional y, al estar depurado de marcas diferenciales, absolutamente respetuoso de la pauta de traductibilidad que gobierna la literatura mundial.

Para concluir, me voy a detener con cierto detalle en dos escritores centrales del catálogo de Anagrama, pero que -según voy a tratar de argumentar- en sus escrituras se llevan a cabo dos operaciones filológicas opuestas, pero de todas maneras efectivas para el ingreso en la literatura (latinoamericana) mundial. Me refiero a Roberto Bolaño y a Guadalupe Nettel, y si digo que sus operaciones son ambas efectivas, en lo que tiene que ver con el objetivo inmediato de "circular", también resalto, desde ya, que lo son en diferente medida, por diferentes razones y con diferentes resultados. Me voy a concentrar en Amuleto (1999) y Después del invierno (2014, Premio Herralde), respectivamente; novelas de las cuales existen traducciones a varias lenguas, con amplia ventaja de Después del invierno que, según consigna el sitio web de la editorial, hasta el momento fue traducida a nueve.

Amuleto es una narración en primera persona asumida por Auxilio Lacouture, una poeta uruguaya que se refugia en un baño de la UNAM durante la violación de la autonomía universitaria y la posterior matanza de Tlatelolco en 1968. Desde ese lugar reconstruye su historia personal en la ciudad de México y su relación con un grupo de jóvenes poetas entre los cuales se encuentra Arturo Belano, uno de los protagonistas de Los detectives. Con este esquema básico alcanza para dar cuenta de las múltiples pertenencias culturales y nacionales contenidas de algún modo en el relato: Auxilio es uruguaya, Arturo, chileno, y ambos habitan la ciudad de México.

La multiplicidad de pertenencias así como el destierro nutren, del mismo modo, Después del invierno. La voz narrativa, siempre homodiegética, se la reparten dos personajes: Claudio, un cubano residente en New York y empleado en una editorial, y Cecilia, una mexicana radicada como estudiante en París. Las narraciones se alternan en los sucesivos capítulos y avanzan con las historias personales de los dos personajes hasta que, en determinado momento, sus destinos se cruzan tempestuosamente para, luego, volver a desencontrarse y, así, dar por triunfadores a la soledad, la muerte y la tragedia. Lo que me interesa subrayar, no obstante, es que también acá, como en Bolaño, el escenario se ramifica (New York y París, La Habana y Oaxaca) y las diferentes subjetividades culturales los cohabitan en el desarraigo y se entrecruzan. 
Y aun así, con estos elementos articuladores compartidos, las narraciones de Bolaño y Nettel resultan, desde el primer abordaje, completamente inasimilables. Se presentan como escrituras mutuamente ajenas, como si, precisamente, se comunicaran en dos lenguajes diferentes. $Y$, en efecto, lo que ocurre es que las textualidades -y no tanto los universos ficcionales- adquieren, respectivamente, dos codificaciones en cierto sentido opuestas: mientras que los personajes de Bolaño habitan todas las lenguas -las variaciones del castellano-, los de Nettel no habitan ninguna. Si la lengua de Amuleto, de sus personajes y narrador, da cuenta de múltiples ubicaciones -a veces superpuestas, a veces encapsuladasen la geografía global, la de Después del invierno no posee arraigo alguno, es una lengua flotante, inidentificable, entre geografías y subjetividades, al punto de que -si no, por supuesto, las biografías- los discursos de Cecilia, la mexicana en París, y de Claudio, el cubano en New York, -su fraseo, paisaje verbal y pulsoson perfectamente intercambiables.

Así, vamos a ver que la voz de Auxilio representa por sí misma, sin que sea necesario que ella u otro personaje informe explícitamente que proviene del Río de la Plata, una ubicación en el mundo. Auxilio es uruguaya, o dado el caso argentina, no tanto porque dice que nació en Uruguay y se trasladó a México, sino, antes, porque así lo da a entender su registro léxico y morfológico, la forma de su palabra, que, por supuesto, no se corresponde tampoco con el del sujeto autor Bolaño. Digo, eventualmente, "argentina” porque bien podría serlo, pero también para que quede claro que se trata de una identidad lingüística y cultural, antes que nacional; una identidad, en cualquier caso, localizable en el mundo empírico. Elijo, para ilustrar esta condición, un pasaje que, por lo demás, resume gran parte del argumento: "Así que yo me hice amiga de esa familia. Una familia de chilenos viajeros que había emigrado a México en 1968. Mi año. Y una vez se lo dije a la mamá de Arturo: mirá, le dije, cuando vos estabas haciendo los preparativos de tu viaje, yo estaba encerrada en el lavabo de mujeres de la cuarta planta de la Facultad de Filosofía y Letras de la UNAM" (37). El voseo -como se observa- en tanto marca identitaria que también da cuenta de una representación localizada del mundo, se manifiesta no solo en los pronombres, sino, como es de esperar, en las declinaciones verbales señaladas tipográficamente con una siempre volátil, pero en este caso aun así existente, tilde. Y, si bien podría oscilar o desde el primer momento aparecer elidido por la condición desarraigada de la narradora, va a constituir un elemento estructural del personaje, que también es el narrador, a lo largo de todo el relato.

Estas marcas que informan sobre diferentes ubicaciones en el territorio del castellano y también, en la medida que la lengua es ideología (Voloshinov), de una cosmovisión, van a definir, de la misma manera que en el caso de Auxilio y respectivamente, a todos los personajes que habitan la ficción de Bolaño. El rey 
de los putos, al que va a desafiar Arturo Belano, por ejemplo, así lo confirma: “¿Quién es quién, buey?, dijo el Rey. ¿Quién es ése?, dijo Arturo y señaló el bulto en la cama. El contralor dirigió una mirada inquisitiva hacia el fondo de la habitación y después miró a Arturo y a Ernesto con una sonrisa vacía. El Rey no se volvió. ¿Quién es?, dijo Arturo. ¿Quién chingados eres tú?, dijo el Rey” (83). Tanto en lo que respecta a la opción pronominal de la segunda persona como al repertorio léxico, el Rey muestra un tipo de pertenencia específica, una -vale resaltar- que tampoco coincide con la del sujeto que asume la función autor, Bolaño, pero que no por eso es la misma que la de la narradora, Auxilio. De modo que, con solo recorrer unas pocas líneas, vemos tomar forma un paisaje verbal, identitario e ideológico que se proyecta al menos hacia tres tipos de locaciones, diferentes, desde ya, pero también solidarias para la eficacia narrativa.

Quiero dejar constancia, no obstante, de que estas subjetividades, apuntaladas por sus respectivos registros dialectales, no son, no obstante, compartimentos estancos, sino que, por momentos, aparecen “contaminadas” o, mejor dicho, mimetizadas entre sí, lo cual -a mi entender- las estaría convirtiendo en configuraciones auténticamente atravesadas por el Zeitgeist de nuestra era global. Dice, por ejemplo, Auxilio en un diálogo consigo misma:

¿ruido de botas?, ¿ruido de botas claveteadas?, pero che, me dije, ya es mucha coincidencia, ¿no te parece?, ¡ruido de botas claveteadas!, pero che, me dije, ahora sólo falta el frío y que una boina me caiga encima de la cabeza, y entonces escuché una voz que decía algo así como que todo estaba en orden, mi sargento, puede que dijera otra cosa, y cinco segundos después alguien, tal vez el mismo cabrón que había hablado, abrió la puerta del baño y entró. (42)

La interjección “che”, una marca característica, incluso hasta trillada, de la variación rioplatense, va a convivir en este pasaje enunciado por Auxilio con un curioso "cabrón" que es tan ajeno a ese registro como propio de otras constelaciones dialectales, las que, según informa la RAE, pueden ser varias, pero no rioplatense, uruguaya o argentina:

cabrón, na

3. adj. coloq. Cuba y Méx. Dicho de una persona: Experimentada y astuta. U. t. c. s. 4. adj. coloq. Cuba. Disgustado, de mal humor.

5. adj. malson. Méx. Dicho de una persona: De mal carácter. U. t. c. s.

9. m. Bol., Chile, Ec. y Ven. Rufián que trafica con prostitutas.

En referencia a Bolaño, Rebecca Walkowitz ha anotado que "Readers of his Spanish-language editions have noted that his diction is not reducible to Chilean, Mexican, or Iberian Spanish. His novels seem translated, in part because they 
combine several regional idioms and seem to have no one native tongue" (17). En vista de lo expuesto arriba, creo que Walkowitz percibe correctamente cuál es tal vez el rasgo distintivo por excelencia de la escritura de Bolaño; se equivoca, no obstante, en sus conclusiones. En efecto, en las ficciones de Bolaño es posible identificar múltiples localizaciones dentro de la diversidad del castellano. Ya sea esto porque los personajes las encarnan y las exhiben o porque el narrador, por momentos, pareciera habitar la zona de intersección. Esto, sin embargo, no es lo mismo que "no poseer una lengua nativa"; muy por el contrario, la textualidad de Bolaño opera de manera que todas las "lenguas" aparecen convocadas y desjerarquizadas, también contaminadas, pero nunca, jamás, vaciadas. La distancia entre una afirmación y otra es abismal, es la que va entre la nada -lingüística, idiosincrática- y el todo. Este error de lectura -aunque, o precisamente porque, no creo que Walkowitz lea a Bolaño en original-, a su vez, la conduce a sugerir que sus novelas "parecen traducidas" y, por lo tanto, ubicarlas en el corpus de la escritura born-translated. Nada más desacertado: ¿cómo traducir, por ejemplo, el repertorio de marcas dialectales que he examinado arriba? ¿Cómo hacer una transferencia - una que sea fidedigna y verosímil- de esa diversidad "castellana" al checo, al ruso o al alemán? ¿Es, en este sentido, la escritura de Bolaño, realmente, una escritura destinada por naturaleza a circular -sin obstáculos o reduccionismos- entre espacios culturales y lingüísticos? Más aún, "Born-translated novels approach this system opportunistically": ¿se puede decir que la escritura de Bolaño es oportunista? Voy a dejar las respuestas en suspenso, para ocuparme por un momento de Después del invierno, un tipo de escritura que sí da muestras de fundarse en el principio de la neutralidad lingüística y, por lo tanto, haber sido concebida como "pretraducida" o, en su defecto, reacondicionada como tal en el proceso de edición.

Después del invierno se abre, esperable y curiosamente, con el siguiente epígrafe de Bolaño: "Follar es lo único que desean los que van a morir”. El pasaje pertenece a "Literatura + Enfermedad = Enfermedad", un texto incluido en el póstumo El gaucho insufrible (2003). El uso de la expresión "follar" -cualquier lector con una sensibilidad promedio lo percibe- le asigna de inmediato una pertenencia peninsular al enunciado, y por extensión al sujeto de la enunciación. En las otras localizaciones del castellano, la expresión puede tomar muchas formas, pero "follar" es marca inconfundible de la variación hispánica. En el texto de Bolaño, esta expresión, sin embargo, va a convivir, por ejemplo, con el mexicano "chaparro", con lo cual también este texto remite a una subjetividad definida por los arraigos múltiples, no a una sin arraigo identificable. La cita, puesta en la posición protagónica de epígrafe, es esperable porque la novela tematiza tanto la enfermedad como el amor y porque el legado de Bolaño pareciera ser ineludible para las generaciones posteriores de escritores latinoamericanos, 
pero, acaso más aún, porque se trata también de un libro, y de una configuración de sujeto autor, que se inscribe dentro de la tradición descentrada y, declaradamente, posnacional que, en el marco de la actual fase de la globalización, Bolaño encarna por excelencia. Resulta curiosa, sin embargo, porque de ahí en más la novela pareciera redactada, justamente, para rebatir el uso identificador de la lengua que Bolaño hacía para construir sus personajes y su escritura en general.

No hay en la escritura de Nettel, que se expresa en paralelo como la voz del cubano Claudio y de la mexicana Cecilia, mayores señas de pertenecer a alguna locación específica del castellano. No hay en toda la trama textual más que escasos rastros de los culturemas - giros, fraseos, marcas léxicas o morfológicas- que se podrían esperar de un cubano o una mexicana. No hay, por lo tanto, a no ser por las marcas de género, manera de distinguir un pasaje enunciado por Claudio de uno que pertenece a Cecilia. En la escritura de Nettel, las pertenencias, que al mismo tiempo serían lingüísticas, culturales e ideológicas, aparecen aplanadas, reducidas a datos biográficos de una infancia remota y borroneada en Oaxaca o La Habana. Por eso, si se las considera por separado, aisladas de su contexto mediato y del hilo conductor general, las unidades sintácticas que van tejiendo el argumento del relato no podrían ser atribuidas a ninguno de los dos personajes o, dado que, finalmente, ambos emplean el mismo registro -uno que, se podría decir, solo existe en la literatura (latinoamericana) mundial-, intercambiadas entre sí sin que eso produzca algún tipo de desfasaje o contradicción:

La forma en la que pronunció la palabra "todo" me hizo gracia. Pensé que al menos en mi cuarto no ocurría nunca nada. Yo no hacía fiestas, ni llevaba amigos a mi casa. Tampoco tenía pareja, ni me entregaba a orgías o a largas y ruidosas sesiones de onanismo. Lo único que tenía era un miserable radio, y, al parecer, eso le molestaba, Por otro lado, si la pared era tan fina como decía, tampoco él tenía una vida privada que pudiera dar envidia. En pocas palabras, el vecino era un infeliz, igual que yo, y quizás por solidaridad acepté hacer lo que me pedía en vez de mandarlo a la mierda. Así que me puse las pantuflas, cerré la puerta tras de mí y entré a su departamento.

(Nettel 79)

Por el contrario, lo que sí es hallable en el Después del invierno son algunas indicaciones, guiños, que dan cuenta de que los narradores no poseen un horizonte cultural compartido con el lector ideal y que, por lo tanto, en ocasiones, debe ser “asistido". Señas que permiten deducir que el texto fue redactado en vista de una recepción internacional o que, de otro modo, la mediación contribuyó con su trabajo para aligerarlo del espesor cultural menos digerible.

En un determinado momento, Claudio se traslada mentalmente a su infancia y los recuerdos, que también son un ineludible retorno al arraigo cultural, lo invaden: "Vuelven a mí las calles malolientes y estropeadas de La Habana Vieja, 
el calor pegajoso al que nunca logré acostumbrarme, mis hermanos metiendo las manos sucias a la olla donde tarda en cocinarse la malanga, ese tubérculo sempiterno cuyo olor nauseabundo se esparce en toda la casa” (44). Como se advierte, la proyección hacia el pasado trae aparejada una reinscripción de la subjetividad en un dominio cultural localizado que pide cierto repertorio léxico. Aparece, así, el término "malanga” que, de acuerdo, con la RAE proviene del bantú y pertenece a la variación castellana del caribe y Centroamérica. El término, para el castellano local, un préstamo necesario para designar una realidad propia de la región, no tiene equivalente en el castellano neutro o en otras lenguas occidentales: malanga es malanga. O, como aclara el texto a continuación, respondiendo de manera anticipada a una recepción ajena al horizonte cultural del narrador, un tipo de "tubérculo". Puesto que el texto "quiere" superar la inscripción local para circular entre dominios culturales, la aparición del vocablo por razones ineludibles reclama una compensación semántica que, si solo estuviese destinado a permanecer en el circuito del castellano(/bantú) local, sin duda no necesitaría ofrecer.

Pero también en pasajes donde ya no es posible identificar resistencias léxicas, se puede inferir que el texto está dirigido a interpelar a un lector ajeno al sistema cultural de los personajes. La llegada de Claudio a París en el segundo encuentro entre los dos protagonistas aparece narrada por Cecilia de la siguiente manera: "Claudio dejó su maleta en la entrada y esperó a que le sirviera el desayuno. En nuestro continente acostumbramos comer a esas horas mucho más de lo que yo le estaba ofreciendo. Me dije que su hambre debía ser infinita después de aquel viaje transatlántico y me sentí avergonzada de no tener más que pan, jugo y café en mi despensa” (155). ¿A quién se dirige la aclaración “en nuestro continente acostumbramos...”? El determinante posesivo "nuestro" y el correspondiente pronombre implícito pueden ser inclusivos o exclusivos en lo que refiere al receptor del mensaje, pero, si se supusiera que la información que continúa es conocida por el interlocutor, entonces el enunciado no tendría ningún sentido. "Nuestro continente" es América Latina, el lugar de proveniencia tanto de Cecilia como de Claudio, o tal vez de los mexicanos en general, de Nettel y de Cecilia, pero, evidentemente, no el del receptor del mensaje. Que sea "nuestro", en este caso, implica que no es del lector implícito - uno que habría que suponer ante todo no latinoamericano- y que, por lo tanto, la información relativa a la cantidad de comida que se consume al otro lado del Atlántico es nueva y relevante para que ese mismo lector pueda seguir el argumento.

Junto con esta vaga pertenencia lingüístico-cultural de los narradores y de los recursos dirigidos a allanar una recepción internacional, el texto también tematiza explícitamente el desarraigo de los personajes. Tom, quien termina por 
consolidarse como la pareja de Cecilia, es de origen italiano, pero también con un pasado en New York y residente en París. En una conversación con Cecilia, comenta esta (no) pertenencia múltiple y la identidad que asumiría para sí:

- ¿Y tú de dónde te sientes? -pregunté.

-No me siento ni francés ni totalmente italiano, mucho menos estadounidense. En realidad, soy un ser fronterizo. Ahí es donde me encuentro cómodo, en las zonas intermedias. Mira el bulevar por ejemplo. Pertenece al XIème arrondissement pero se asemeja mucho más al XXème que está ahí, del otro lado del cementerio. ¿No te parece?

-Supongo que sí -contesté, por decir algo.

-Los países donde mejor estoy son Francia e Italia. He vivido muchos años oscilando entre ellos, sus capitales están llenas de inmigrantes de otras latitudes. Aunque no lo creas, muchos se sienten en casa. (87)

Este lugar de intersección en el que dice sentirse cómodo Tom no es, no obstante, el que parecieran ocupar Cecilia y Claudio. Sí, por el contrario, el que habitaría un sujeto de la enunciación que se permite hacer convivir en su discurso "follar" y "chaparro". Se trata otra vez de la diferencia que va del todo a la nada. Los personajes de Nettel, si se da crédito a sus maneras de expresarse, se definen antes por la primera caracterización que ofrece Tom: "ni francés ni totalmente italiano, mucho menos estadounidense", nada. De un ser "fronterizo", habitante de las "zonas intermedias" sería tal vez esperable encontrarle marcas que lo inscribieran en diversos lugares, su patrimonio cultural sería, así, todo.

Creo también que esta es la diferencia que va de un texto escrito -redactado/ acondicionado- para no oponerle resistencia a la recepción desterritorializada, es decir, a la de un mercado impersonal y, por eso mismo, sin límites identificables, a uno que, por naturaleza, porque se nutre de una cierta experiencia vital en correspondencia con los desplazamientos identitarios producidos por la actual fase de la globalización, no puede más que exhibir y capitalizar la pertenencia múltiple. Las dos escrituras, cada una a su manera, son eficaces en lo que refiere a los principios constitutivos de la literatura mundial, las dos pueden aportar evidencia de que han entrado en circulación internacional y que han recibido reconocimiento en dicho nivel. Una, la que ha borrado toda marca de pertenencia, se corresponde, según la terminología de Mijail Bajtin, con la novela monológica, donde una voz, que no es la voz de nadie sino la del mercado internacional, conduce la narración. La otra, la que convoca todas las pertenencias, a la novela polifónica. Bolaño y Nettel serían, así, dos nombres posibles que adquiere la inscripción en la literatura latinoamericana mundial. Dos modos de inscripción, sin embargo, completamente disímiles. El primero interpela porque representa (también) la localización del lector, sea quien fuere, esté donde esté. El segundo triunfa en el mercado internacional, en particular en la venta de 
derechos de traducción -la mediación, por intervención o por influjo, ha generado garantías para ello-, pero fracasa como literatura porque ha sacrificado autenticidad y se percibe impostado; atado a demandas extraliterarias. La eficacia, en términos de circulación, se inclina, no obstante, hacia el segundo: si Amuleto hasta el momento -a casi veinte de años de su primera publicación- fue traducida a cuatro lenguas, Después del invierno lo fue, en cuatro años, a nueve.

Diría, en oposición a lo que sostiene Walkowitz y según lo expuesto, que lo que sucede es que la escritura de Bolaño no ha nacido traducida ni ha pasado por un proceso de normalización. Constituiría, en este sentido, un artefacto anómalo en el corpus de la literatura (latinoamericana) mundial. Es anómalo porque la fórmula habitual, la de éxito, es la que, con el fin de circular, se libera de las codificaciones dependientes de contextos específicos o, dado el caso, introduce recursos didácticos que faciliten la decodificación. La escritura de Nettel, por el contrario, sí ha nacido traducida, sí ha sido adaptada para interpelar a un incierto -o imaginado- lector sin residencia alguna. La escritura "Bolaño" es la que genera una globalización en manos de los sujetos, una que se alimenta de los avatares de una experiencia vital contemporánea; la escritura "Nettel” es la que aparece condicionada por los requerimientos de una globalización guiada por las necesidades de los mercados. Las dos escrituras pertenecen al catálogo de Anagrama, la primera por excepción -y sorprende-; la segunda, por norma -y tranquiliza-.

Y si Bolaño constituye una excepción, se debe a que, si bien no pertenece a la literatura regional/nacional/local, tampoco respetaría las convenciones que hoy se le impone a la literatura para devenir mundial. Lo mismo da si los textos de la literatura mundial nacieron pretraducidos o fueron acondicionados durante el proceso de producción/traducción, en cualquier caso se trata de que, por regla general, contienen una serie de atributos básicos, esto es, cierta transparencia comunicativa, bajo riesgo formal, respeto por la pauta de traductibilidad, carencia de accidentes culturales muy marcados, etc. Lo que estaría informando la escritura de Bolaño -y es en percibir esto donde falla cierta zona de su descendencia- es que la recepción internacional no debería ser subestimada o, dicho de otro modo, que tal vez, en lugar de un aplanamiento cultural, lo que está pidiendo la recepción internacional es textos polifónicos que den cuenta de la diversidad global. 